\title{
Urban change as an untapped opportunity for climate
} adaptation

\author{
Monika Egerer ${ }^{1,2 凶}$, Dagmar Haase $\mathbb{1}^{3,4}$, Timon McPhearson $\mathbb{i D}^{5,6,7}$, Niki Frantzeskaki ${ }^{8}$, Erik Andersson $\mathbb{i D}^{9,10}$, Harini Nagendra ${ }^{11}$ and \\ Alessandro Ossola (iD) $12,13,14$
}

Urban social-ecological-technological systems (SETS) are dynamic and respond to climate pressures. Change involves alterations to land and resource management, social organization, infrastructure, and design. Research often focuses on how climate change impacts urban SETS or on the characteristics of urban SETS that promote climate resilience. Yet passive approaches to urban climate change adaptation may disregard active SETS change by urban residents, planners, and policymakers that could be opportunities for adaptation. Here, we use evidence of urban social, ecological, and technological change to address how SETS change opens windows of opportunity to improve climate change adaptation.

npj Urban Sustainability (2021)1:22; https://doi.org/10.1038/s42949-021-00024-y

\section{INTRODUCTION: DYNAMIC CITIES IN CHANGING CLIMATES}

Change in social-ecological-technological systems (SETS) transforms and reconfigures urban systems as a continuous, dynamic, and inevitable process ${ }^{1,2}$. Drivers of urban SETS change are intrinsically multidimensional and multiscalar, driving change at both temporal (i.e., short to long) and spatial (i.e., local to global) scales $^{1,3}$. SETS change involves feedback across and between social, ecological, and technological systems (Fig. 1). The heterogeneity, hybridity, and dynamism of urban systems affect the intrinsic ecological-biophysical, social-economic-governance, and technological-infrastructure makeup of cities ${ }^{4-7}$.

Social change, including changes in demographics, governance, and economics, occurs at the level of individual human perceptions and behaviors, as well as at the higher level of society and its institutions ${ }^{8}$. Ecological and evolutionary change occurs at the scale of urban species populations to the urban macroecosystem and global scale through urban environmental and human-mediated filters ${ }^{9-11}$. Technological change can occur at individual resident and city-scale from adoption and use of technological innovations to the global scale through innovation journeys, new technology adoption via IT, ample digital innovations, and social media networks $s^{6,12}$.

Climate change is a global driver of SETS change ${ }^{4}$. From continental hubs to coastal megacities, climate change drives social transformation and migration, triggers new behaviors and actions, and motivates investments in new infrastructure, but also affects species composition and ecological interactions ${ }^{13}$. Urban infrastructure is increasingly designed to respond to the challenges posed by future climates ${ }^{3,14-16}$. In this evolving climatic context, SETS change is often considered the end product and outcome of contemporary urban societies driven by the need for economic growth and emancipation from poverty ${ }^{17,18}$. SETS change is also a driver of climate change itself and feeds back over time and space to influence urban livability, in terms of human well-being as well as ecosystem health.

While city residents and governing bodies are seeking SETS strategies to proactively improve the capacity to cope with and adapt to climate change ${ }^{19-21}$, SETS change is still often only identified as a driver, provoker, or a reinforcer of climate change impacts, rather than as an opportunity to ameliorate or mitigate impacts. For example, urbanization increases urban populations, energy consumption, and therefore exacerbates climate change ${ }^{22}$, setting in motion perverse reinforcing loops and vicious cycles ${ }^{23}$. In turn, climate change can cause massive migrations of people to and from urban areas, and population displacement and vulnerability, causing a further change in urban SETS now and in the future ${ }^{24}$. Yet, we know relatively little about how we can leverage, guide, embed, or even design system-level SETS change, both as a driver and mitigator, to increase urban climate change adaptation. Though specific and limited transformation within SET subsystems is achievable and active, we are still missing holistic strategies that cut across SETS and strategies fundamentally anchored in SETS thinking.

To enable explicit SETS strategies and thinking for urban climate adaptation requires moving beyond the cause-effect climate change adaptation narrative to a more proactive approach that acknowledges hybridity and interrelations across SETS. With a better understanding of urban complexity, we argue that there is ample opportunity to steer change in places where plans, strategies, and instruments are already developed and ready to use. If triggers and opportunities of SETS change are recognized, interacting properties of urban SETS can be utilized for immediateto long-term systemic climate change adaptation. Actions can vary from people's everyday actions to broad-sweeping government programs. A SETS understanding should support and align such institutional diversity across scales by recognizing the need to

\footnotetext{
${ }^{1}$ Department of Life Science Systems, School of Life Sciences, Technische Universität München, Freising, Germany. ${ }^{2}$ Department of Ecology, Ecosystem Science/Plant Ecology, Technische Universität Berlin, Berlin, Germany. ${ }^{3}$ Helmholtz Centre for Environmental Research e UFZ, Department of Computational Landscape Ecology, Leipzig, Germany. ${ }^{4}$ Humboldt Universität zu Berlin, Institute of Geography, Berlin, Germany. ${ }^{5}$ Urban Systems Lab, The New School, New York, NY, USA. ${ }^{6}$ Stockholm Resilience Centre, Stockholm University, Stockholm, Sweden. ${ }^{7}$ Cary Institute of Ecosystem Studies, Millbrook, NY, USA. ${ }^{8}$ Centre for Urban Transitions, Faculty of Health, Arts and Design, Swinburne University of Technology, Melbourne, Australia. ${ }^{9}$ Stockholm Resilience Centre, Stockholm University, Stockholm, Sweden. ${ }^{10}$ North-West University, Unit for Environmental Sciences, Potchefstroom, South Africa. ${ }^{11}$ Azim Premji University, Bangalore, India. ${ }^{12}$ Department of Biological Sciences, Macquarie University, North Ryde, Sydney, NSW, Australia. ${ }^{13}$ Department of Plant Science, University of California, Davis, CA, USA. ${ }^{14}$ School of Ecosystem and Forest Science, The University of Melbourne, Burnley, VIC, Australia.

$凶_{\text {email: monika.egerer@tum.de }}$
} 


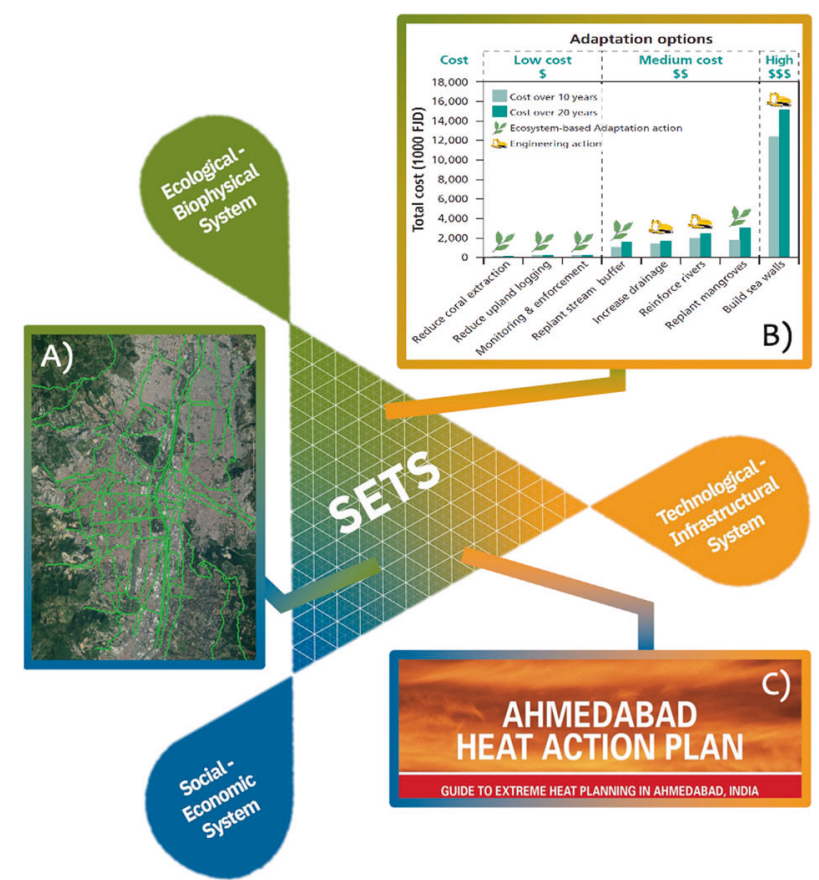

Fig. 1 Reactive actions for climate change adaptation within SETS. A Because of high unemployment, the city of Alcaldía de Medellín, Colombia, trained people from disadvantaged backgrounds to work as gardeners and technicians to implement the Green Corridor program (in green in the map, courtesy Medellin Open Data portal) to cool the city by up to $3^{\circ} \mathrm{C}$ by planting more than 358,000 shrubs and trees, while reducing crime and improving public health. B The town of Lami in the Republic of the Fiji Islands is evaluating adaptation scenarios for climate change and sea-level rise. Economic costs of integrated nature-based and technical solutions are often far lower than those related to traditional engineered approaches (https://ian.umces.edu/pdfs/ian_report_392. pdf). C The increasing need to protect vulnerable communities living in slums in Ahmedabad prompted the local government to start a Cool Roof program in 2013. Building upon that program, the city has released a more comprehensive Heat Action Plan tapping into several initiatives involving both local communities and infrastructure (https://www.nrdc.org/sites/default/files/ahmedabadheat-action-plan-2019-update.pdf). SETS framework sensu Depietri and McPhearson (2017).

include multiple actors with diverse capacities and power in contributing to and identifying multiple pathways toward climate adaptation ${ }^{25}$. In moving to a SETS-based adaptation policy and planning approach, it is important to (1) ensure openness and inclusivity of different cultures, ages/generations, viewpoints, and knowledge, and (2) support novel combinations of social, ecological, and technological subsystems into adaptation pathways that offer opportunities for broad participation and empowerment, provided public support.

In this perspective, we advocate for channeling current adaptation actions through ongoing urban SETS change processes. Doing so can create opportunities to proactively design and build adaptive capacity in towns, cities, and urban regions overall. SETS change can be purposefully designed and actively embedded in both individual- and societal-level changes by using institutional design ${ }^{19,26}$, cocreation, and coproduction ${ }^{27,28}$. Within a framework that embraces SETS change across various social agencies as a means for climate change adaptation, we discuss where we see opportunity while simultaneously acknowledging the hyperdiversity of cities, the context dependence of urban SETS, and that everyday human actions range from selfish to altruistic. These complexities ultimately create challenges in how such a perspective is adopted and leveraged, and likely explain why existing frameworks often subscribe to reactive rather than proactive paradigms for transition ${ }^{27,29}$, namely, a perception that deliberate SETS change cannot be planned, designed, or actively (co)produced. Active SETS change calls for acknowledging urban complexity and diversity, recognizing triggers of change, the variety of pathways that enable agency, and being prepared for change at the individual to the institutional level. We focus on constructive approaches to advocate for a paradigm shift, one that sees SETS change not as a monolithic and undesirable outcome caused by climate change, but rather as a dynamic opportunity to willingly and proactively harness and nudge systemic change for urban transformations toward more desirable, inclusive, and resilient urban futures. We do not position this framework as a solve-all panacea to foreseen climate change impacts across all urban contexts, but rather, such an approach can be implemented alongside existing adaptation frameworks to expand their scope, reach, and effectiveness.

\section{SETS CHANGE AS AN OPPORTUNITY FOR URBAN CLIMATE ADAPTATION}

Knowledge coproduction and uptake of new technology are examples of different ways through which individuals and institutions at various levels navigate and, often proactively, take advantage of SETS change $\mathrm{e}^{1,16}$. Climate change can trigger nonlinear positive tipping points from society and technology that, through feedback, create different-ideally improvedsystem states (Fig. 2) ) $^{3,30}$. For example, in urban forestry plans, forecasted future climate envelopes can offer an opportunity to redesign planting strategies around species more likely to withstand future temperature and rainfall extremes and replace those likely to struggle or fail ${ }^{23}$. For urban communities to acknowledge such changes and strategically steer SETS change requires systems' thinking to accelerate actions for sustainable urban transitions ${ }^{29}$. Changes in urban contexts that are proactive and that harness shared learning among individuals (e.g., among neighborhood residents) or governing bodies (e.g., among regional city climate councils) have optimal potential to further increase urban climate change adaptation through positive feedback ${ }^{3}$. An important consideration is who is included or excluded from these learning and change processes, and therefore which social group adaptation may benefit the most. For instance, tree planting may be a more likely adaptation strategy for wealthier neighborhoods, but difficult to implement in densely packed informal settlements where there is little open space for tree plantings, leaving such communities even more vulnerable. Individual and institutional action and learning across sociodemographic gradients that is experience-based, knowledge-rich, solution-driven, and stakeholder-diverse, are best suited to meet the needs for urban climate change adaptation in a warmer and more extreme world ${ }^{31-33}$.

Urban social, ecological, and technological adaptations to climate change, happening at various levels of social organization, can be embedded in and enabled by SETS change (and vice versa) in different urban contexts. We provide selected evidence from urban green and blue, food and technology systems, all of which are at the epicenter of climate change impacts and are expected to experience more extreme and frequent impacts in the future ${ }^{34}$. The examples illustrate (1) how SETS change may offer more holistic adaptation to new climate regimes, (2) how different pathways for diverse actors can expand the scope of social, ecological, and technological changes to thereby support SET change, and (3) how a SETS perspective may guide urban climate change adaptation and help residents and governing bodies overcome current barriers and limitations. We do not advocate for a linear pathway nor a one-size-fits-all model in which the mechanisms creating change are identical and predictable, but rather we conceptualize nonlinear pathways that acknowledge 


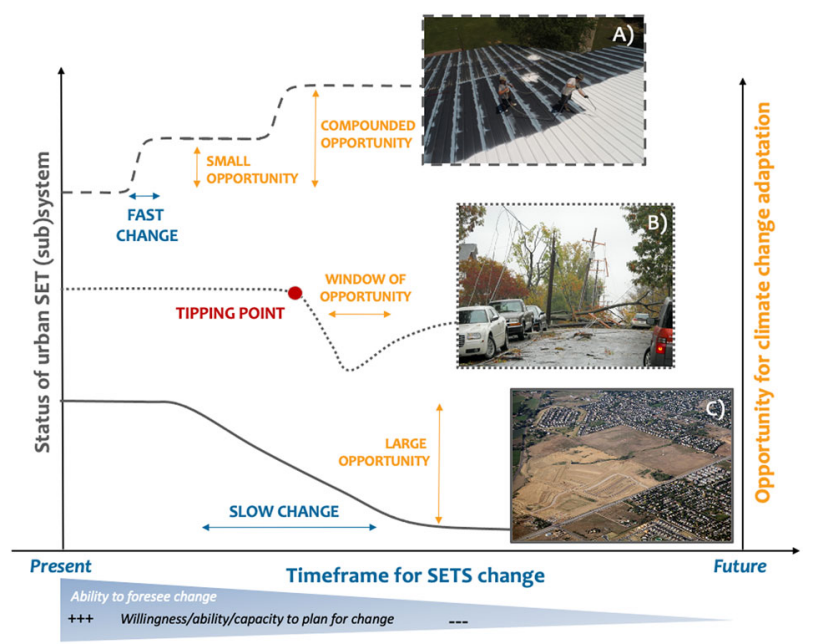

Fig. 2 SETS changes that could introduce elements for climate change adaptation. Urban systems vary in how SETS change occurs, specifically how fast or slow, and how small or large the opportunity for climate change adaptation is. Furthermore, in relation to time, change varies in its predictability-represented here by a fulcrum where the ability to foresee and plan for change in the present is high $(+++)$, whereas the ability to foresee and plan for change moving into the future is low (---). A Relatively small changes, such as the opportunity to paint rooftops white for increasing solar reflectance and reducing urban heat, can occur rapidly; though small, these opportunities may compound the effects over time and space to generate the greater capacity to adapt to climate change (Photo: MO, USA; Courtesy: Patriot Roof Coating, www.pxfuel.com/ en/free-photo-owshf; CC BY-SA 2.0). B Ecological change, such as from extreme weather, may produce tipping points that can provide new windows of opportunity for residents and cities to, e.g., plant more resilient tree species (Photo: post storm Hurricane Sandy, Queens, New York City, USA; Courtesy: Arlington County; https:// www.flickr.com/photos/arlingtonva/; CC BY-SA 2.0). C Other SETS might exhibit a large opportunity to adapt to climate change, such as adapting housing developments for future climate change in rapidly developing arid cities, though this change may be relatively slow (Photo: Thorton, CO, USA; Courtesy: Doc Surls, www.flickr.com/ photos/infrastructure/; CC BY-SA 2.0).

urban contexts and cultural backgrounds (e.g., Global North and South). Nonlinearity and complexity are fundamental properties of SETS tipping points and transitions ${ }^{35}$. In urban SETS, change in one subsystem may have unforeseen impacts on another subsystem, and this is most likely location- or context-dependent. Acknowledging urban complexity and diversity ${ }^{36}$, we highlight principles that urban strategic planners may apply into a specific urban context to design effective policies and planning interventions.

Through these interventions, we show how SETS change can occur at different spatial and temporal scales in cities, from local ecosystems (e.g., yard parcel) to the urban macrosystem scale, from post-disaster abrupt interventions by the city government to progressive behavioral changes by residents (Fig. 2). For example, rebuilding cities struck by wildfires or hurricanes triggered by or exacerbated by climate change (e.g., Paradise, CA; New Orleans, LA) can provide a blank canvas and opportunity to design SETS change with elements known to enhance urban climate change adaptation. In older, more developed cities, on the other hand, smaller SETS changes at an individual or community social level can be further promoted to compound smaller interventions over time, potentially positively stimulating climate change adaptation ${ }^{16,30}$.

Below, we draw examples from several cities across the Global North and South, from the United States, Latin America, East Asia, Africa, Australia, and Europe that represent different patterns of urbanization, historical development, urban growth, and renewal. Furthermore, these cities represent a diverse range of social-ecological, technical, biophysical and institutional constraints, and contexts. For example, residents' attitudes on environmental stewardship, and government policies toward urban greening differ with city contexts ${ }^{37}$. Cities differ in society, climate, and ecology. Thus, triggers of change and contingency plans to prepare for change differ across urban and cultural contexts as demonstrated in the recent COVID-19 pandemic ${ }^{38}$. As climate change has no borders, we take a broad geographic perspective to highlight promising examples of change across a diverse range of urban SETS. Although we structure the following examples into social, ecological, and technological systems, this is an artificial divide, as these spheres are interrelated and interdependent. We describe changes by highlighting their main intervention typologies and characteristics.

\section{Social change}

Urban social climate change adaptation involves learning-focused interventions like experimentation, governance initiatives that test and showcase sustainable solutions, and social networks and movements that enhance knowledge exchange. Social learning occurs at the individual resident, community, and city to international institutional levels ${ }^{25}$ and enables deeper transformations across social classes, communities of interest, and practice. We discuss some urban social changes at various levels to showcase examples where social change has harnessed ecological and technological opportunities to achieve active and deliberate SETS change for climate adaptation. Furthermore, we show how enabling social agency at appropriate scales can promote deliberate SETS changes for climate action ${ }^{25}$. Here, agency is intended as the capacity of individuals and groups to act independently and have freedom of choice and can be enabled through institutional spaces, settings, and environmental policy ${ }^{36}$. We support acknowledging and including diverse individuals, groups, and their partnerships involved in urban SETS change. Because cities are deeply unequal social, cultural, and economic environments, and social change needs to keep social justice principles at its core to advance urban sustainability.

At the city resident level, enabling and nurturing city residentlevel agency for climate change adaptation planning can foster ownership of change implementation and stewardship of change over the long term, making climate change adaptation under urban SET change a reality now and in the future. While everyday human behavior is inherently complex and contradictory particularly around environmental stewardship and climate change (e.g., choice of transportation and food purchasing ${ }^{39,40}$, there are promising social movements and political mobilization of urban citizens (e.g., Fridays for Future) ${ }^{41}$. Urban social change can be scaled to address the challenge of climate adaptation by trialing and showcasing sustainable solutions across many places $29,42,43$. Heightened stewardship may in turn increase interest in change or a reorientation to how SET change is perceived as an opportunity for climate change adaptation.

Urban agriculture highlights social change at the city resident level and can demonstrate the value and diversity of resident actions and choices in climate change adaptation. Agricultural practices involve knowledge coproduction and action around climate change impacts to plant production ${ }^{44,45}$. For example, when experiencing acute climate shocks (e.g., plant mortality, crop loss, and water scarcity), community gardeners in drought-stricken areas like Australia and California learn individually and through communication with the gardening community what certain crop plants will not survive under present and future climate conditions ${ }^{46,47}$. Gardeners experiment with combinations of plant species and varieties, sharing and learning with one another the observations on what species survived extremes to redesign resilient urban garden systems. This suggests that, on a small scale, urban gardeners make systemic changes to garden plots 
and to their behaviors, building up their adaptation capacity to a changing climate through knowledge coproduction. Gardens can also highlight the interrelations among SETS subsystems in adaptation where plants and people interact within a changing climate context ${ }^{46}$. Local government policy and action may assist in climate change adaptation in urban agriculture by enabling resident-level agency at the appropriate scale and context. In Quito, Ecuador, city-funded local environmental NGOs train urban farmers to shift and diversify crop plants to native species, and train in water conservation management ${ }^{48}$. In Durban, South Africa, agronomists are piloting crops popular with urban residents to test the survival of and learn about the palatability of crop varieties more resilient to water shortage and increased temperatures and creating community-based adaptation plans for improved implementation ${ }^{48}$. In Gorakhpur, India, nonprofit groups are working with urban farmers to leverage nature-based adaptation to implement climate-resilient farming strategies (including crop rotations) and mainstreaming climate risk information via weather advisory text messages to guide changes to irrigation and harvesting ${ }^{49}$. Informal settlements in South African and Indian cities forage and cook with wild plants based on knowledge transmitted by older residents and migrants from other areas but adapted to changing conditions. These climate change adaptations at the household to community level have boosted crop yield and incomes. Engagement of city government with local partners and urban citizens reflects how we may find sweet spots for enhancing climate change adaptation through collaboration and agency creation across social levels ${ }^{25}$.

At the local city to urban region level. Most cities are implementing plans and policies for climate change adaptation. In Ahmedabad, India, the Municipal Corporation and civil society groups implemented a Heat Action Plan (HAP) designed with public health and NGO institutions to prepare residents for extreme heat (Fig. 1). The Plan - a SETS change triggered by an extreme heat wave-implemented mapping and alerting of highrisk heat areas, a heat warning system for residents, and training for healthcare professionals. Now influencing heat action plans in many other cities, HAP exemplifies how responsive governance change in one city can catalyze change in cities nationwide. This shows how governance changes at the local city level trickle down to individual/community behavior change by urban residents, but also shows how current adaptation approaches follow reactive paradigms and could be pushed to interactively and proactively approach change. To use another example, cool roofs (e.g., in Fig. 2A) are implemented both reactively-actions to immediately mitigate extremely high temperatures-and proactively-climate contingency legislation to prepare for future chang $\mathrm{e}^{50}$.

From learning- and stewardship-focused changes, urban social changes also include establishing regional city-to-city networks and platforms with evidence on effective solutions. Networks can catalyze peer-to-peer learning and knowledge transfer among city officials on efficacy and potential of solutions and approaches beyond geographical boundaries ${ }^{19,51}$. Activation, mobilization, and the creation of city networks through, e.g., citizen-led initiatives, NGOs, and technology, could collectively respond to climate change adaptation and may accelerate the lessons learnt and practices or solutions that work across geographies and scales. Such networks could facilitate horizontal, nontraditional, and new types of collaboration among individual to global agents, moving beyond traditional top-down and bottom-up initiatives ${ }^{52,53}$. Indeed, the role of governments and the role of scientists in city networks remain important, but at most, research has showcased how social change is a multi-actor and multi-issue response and driver to SETS change ${ }^{19,54}$.

At the global scale. Civil movements and initiatives at the larger international level are also important governing bodies for promoting change. The Sustainable Cities platform in Brazil, the OPPLA and ClimateAdapt solutions' platforms in the European Union (see https://climate-adapt.eea.europa.eu/eu-adaptationpolicy/sector-policies/urban), thematic global networks such as 100 Resilient Cities and NATURA (see www.nature-net.org), and an emerging number of urban-focused solutions are platforms for sharing economy, nature-based solutions and circular cities among policymakers and government officials. These organizations are well positioned to retrofit change on global governance structures with elements aimed at building climate change adaptation. For instance, The Asian Cities Climate Change Resilience Network (ACCCRN) connects city governments, NGOs, and funding agencies across six countries (India, Indonesia, Thailand, Vietnam, Bangladesh, and the Philippines) to support and invest in knowledge and community to regional capacity building for urban climate change adaptation. With the mantra 'Building Community of Inclusive Urban Climate Change Resilience,' the ACCCRN works at the global scale but the community level with a strong focus on amplifying local resident and community voices, particularly of women and low-income urban populations (see acccrn.net) ${ }^{55}$. One recent project in Dong Ha City, Vietnam, provides low-interest credit loans to poverty households to retrofit homes for flood and storm resistance. Overseen by the ACCCRN, the credit fund will be locally managed by the provincial Women's Union. Retrofitting and redevelopment is one example of planned changes that could be leveraged for climate change adaptation at a city-wide scale.

Such international-level governance changes aim to open and share knowledge on solutions and approaches to implement and "make these solutions to work on the ground" of cities searching for information for valid alternatives ${ }^{56}$. Important, however, is that such continent-wide and global commons governance initiatives should be maintained and even strengthened beyond calm conditions to prevent superficial initiatives that do not withstand nor come to the fore during crises.

\section{Ecological change}

Cities are re-envisioning urban planning to start shifting away from engineered solutions (e.g., hard paving and channeling) toward solutions that use fewer resources (e.g., water or nutrients) ${ }^{57}$, incorporate nature-based solutions ${ }^{58}$, and ultimately mitigate future negative climate change impacts ${ }^{59}$. Concerns for urban biodiversity conservation and extinction of human-nature experiences in cities may shape ecological changes that create novel ecosystems and promote human-nature connections (e.g., through biophilic design $)^{60}$. Ecological systems, both in cities and in the wild, are dynamic and in the perpetual status of the change. Thus, urban ecosystems, under thoughtful and proactive human intervention and management, can offer opportunities to retrofit climate change elements under planned change.

The rapid rates of projected climate change and particularly in cities mean that many plant and animal species will not be able to adapt to new conditions ${ }^{23}$. This warrants creative ecological climate change adaptation changes to support urban biodiversity and associated ecological functions, while ideally promoting climate change mitigation. Many cities are harnessing ecological changes, for example in urban forests, to synergistically promote ecological function and climate mitigation. In Berlin, Germany, city greening and conservation programs are harnessing forecasted climate change conditions, temperature, and drought extremes to guide their urban tree species selection for both pollinators and climate mitigation ${ }^{61}$. Here, selecting trees that, though novel in the city, will bloom at different times to maintain floral resources for wild pollinators in the short annual term, and over the long term, as such, plant species will more likely withstand future weather extremes. Incorporating novel ecological elements can simultaneously maintain ecological functions and adapt cities to 
climate change impacts. Yet, though such urban tree planting initiatives are aimed to build climate resilience and prepare for climate change, there are still many reactive examples where drought- or pest-stricken trees are often replaced with nonclimate-ready species that continue to dominate tree nurseries ${ }^{23}$. New technologies, including drones and hyperspectral remote sensing, could also be implemented to monitor "climate-ready" urban forests to better safeguard ecosystem services.

Bringing nature back in the city combined with climate change adaptation is motivating designing with nature-based solutions $^{19,58,62}$. Solutions employ living plants and soils along with green and blue landscape elements to reduce negative climate change impacts and to make cities more climate-resilient. Green roofs are one popular strategy that can be retrofitted onto buildings to increase climate adaptation of urban assets. The ecological concepts embedded in such nature-based solutions include biodiversity conservation, ecosystem multifunctionality, and multiple ecosystem service provision ${ }^{63}$. For example, green roofs planted across cities by residents and businesses promote various climate-related ecosystem services, including carbon storage and stormwater retention, for climate change adaptation ${ }^{64}$. Rain gardens, such as the $100-m$-long rain gardens in Rotterdam, The Netherlands, show innovative collaboration with urban architects and designers to improve water retention and flooding mitigation ${ }^{65}$. These examples highlight cocreation processes (among citizens, designers, and businesses) and the interactions between ecological and social systems in different urban design frameworks that can inform and guide such socioecological transitions. Biophilic design is another ecological design intervention for climate change adaptation. In Singapore, citizens and institutions are combating both biodiversity loss and climate change challenges through deliberate biophilic design strategies, including biodiverse and heat-mitigating street trees, green roofs, and walls ${ }^{66}$. Here, the Cooling Singapore initiative uses climate change as an opportunity to accelerate adaptation via biophilic design, focusing on biodiversity-rich infrastructure. The Singapore Botanical Garden Learning Forest contains 700 plant species and contributes to heat island adaptation by integrating biophilic design strategies that increase shade cover, vegetation cover, species diversity, and wind flow.

Ecological changes for urban climate change adaptation do and should involve a mix of city stakeholders, including policymakers and planners, citizens, environmental organizations, and private businesses. Ecological adaptations should support cocreation processes and strengthen synergistic interactions between social and ecological systems. City and academic partnership projects are linking ecological components of cities with data-driven technological innovations for climate change adaptation (see below). In Bendigo, Australia, the Shadeways Project leverages fine-grained heat and vegetation/shade data derived from satellite imagery to provide residents with an accessible and easy mapping tool to plan the most thermally comfortable traveling route (https://www.shadeways.net/). Such small localized solutionswhere residents can adapt to extreme temperatures by avoiding urban temperature hotspots-can help build regional climate change adaptation, especially if they can be compounded at larger scales. Providing access to and encouraging the use of novel ecosystems for biophilic interactions and new technology among all urban communities - from low- to high-income, longterm residents to new urban migrants-is critical to make ecological innovations equitable and just. Thus, ecological changes coproduced through city or academic partnerships should consider socioenvironmental justice and engage with all community members in diverse ways to be truly effective in change implementation ${ }^{67}$. Stakeholder engagements may involve new transdisciplinary and cocreation models of, for example, citizen science that create inclusive climate policy change, transform citizen behavior to positively compound ecological climate change adaptation, and support citizens as key agents driving urban climate change adaptation ${ }^{68}$.

\section{Technological change}

Technological changes, including infrastructure change, are rapidly evolving and spreading across urban regions in response to climate change. Technological change for climate change adaptation involves interlinking urban infrastructures and delivering urban services through deployment of digitalization, automation, and similar emerging technologies ${ }^{69}$. "Smart cities" and suburbs promise a quicker, more efficient, and integrated future supported by "big data", the Internet of Things (loT), urban intelligence, emerging, and future technologies. Yet technological changes may also be quite low-tech without digitalization and involve urban citizens retrofitting their homes with their own devices in a self-help fashion ${ }^{70}$. We discuss how climate change can inspire the deployment of technology and infrastructure change aimed at reducing its impacts on the urban economy, optimize energy supply waste management, and continued services for a burgeoning urban populace. While technological innovations can hold promise for climate change adaptation, they should be carefully implemented with potential negative unintended consequences and risks to social justice in mind (e.g., technological "lock-ins", digital divides that amplify social inequality, privacy concerns, and technocratic governance), and benefits to broader society as a common goal ${ }^{71}$. We describe both types and scales of interventions.

Despite technological "smart city" aspirations, most of the world's cities still require a significant departure from the status quo to leverage impactful technological change for climate change adaptation at multiple scales ${ }^{6}$, and to do so equitably across socioeconomic groups ${ }^{71}$. Climate-related technology can be embedded in the world's cities following technological replacement, upgrade, and evolution ${ }^{72}$. This, however, is still the exception rather than the norm, and often practiced on a small scale based on opportunity or need as, for example, a disasterdriven response by city governments ${ }^{73}$. Technological including infrastructural climate change adaptation changes by government, industry, and residents require forward-thinking action now, rather than salience-driven approaches to climate change adaptation motivated by risk $^{73}$. The substitution of old infrastructural assets with more flexible and adaptive infrastructure that can harness loT innovations such as weather sensors could enable "smart" urban meteorology, supporting cities to improve weather forecasting and proactively adapt to extreme events triggered by climate change ${ }^{74}$.

Simple and small actions by urban residents could promote powerful technological and infrastructural advances for climate change adaptation (e.g., participatory and opportunistic crowdsensing $)^{75}$. For example, new "smart" car windshield wipers, deployed on an interconnected car fleet, can improve local realtime precipitation measurements, produce highly accurate rainfall maps, and even capture rainfall events missed by current technology ${ }^{76}$. Similarly, the substitution of traditional public transport shelters with "smarter" ones may provide not only a shelter from harsh weather conditions but also for enhancing ambient urban sensing, intelligence, and climate change adaptation $^{77}$. Thus, urban technological change can, if properly mainstreamed and scaled, heighten city and resident ability to locally predict, respond, and adapt to extreme weather events, like urban flooding or extreme heat.

Most contemporary urban infrastructure systems are relatively inflexible, rigid, and long-lasting ${ }^{6,78}$. Although infrastructure systems are often designed and engineered to meet demands decades into the future, new opportunities to leap-frog using the latest technology for more adaptive approaches can spontaneously arise. Cycles of urban decay and replacement, 
or climate-driven extreme events that may damage or destroy existing infrastructure, offer urban planners, engineers, and architects the chance to update technology. Integrating "green" infrastructure as a nature-based solution for regenerating urban water infrastructure could alleviate forecasted large stormwater surges, as shown for Buffalo, NY, USA. On a small, residential scale, the substitution of old water meters with smarter sensors can increase water savings in drought-stricken cities such as Cape Town, South Africa ${ }^{79}$, the first city in the world to face "Day Zero" and the complete shutdown of its water supply ${ }^{80}$. Water meters implemented in urban gardens can improve irrigation efficiency, reduce crop mortality, and redesign garden systems for future harsher climate conditions ${ }^{46}$. Residents are also adapting to climate change using existing infrastructure and technologies already in hand for microscale adaptation. For example, in Ho Chi Minh City, Vietnam, residents are creatively updating building infrastructure to physically raise homes and shop entrances above flood levels ${ }^{81}$. In Sweden, neighborhood residents collaborate to create roof pipeline networks to prepare for increased stormwater runoff ${ }^{82}$. These examples well highlight how technological systems interact with ecological and social systems for relatively accessible adaptation actions.

On a larger scale, smart water grids can allow cities to improve water shortage and drought management by detecting leaks in real time and optimizing supply through cloud-based systems during times of scarcity (e.g., Australian Water Association). Simply repainting buildings can also manage albedo and mitigate temperature ${ }^{83}$, while nanotechnology promises a future of supercooling materials for retrofitting buildings and new constructions ${ }^{84,85}$. Nordic cities are using active approaches to rebuild cities after permafrost melting by integrating changes associated with soil thawing into a building's foundational design and maintenance for future melting ${ }^{86}$. Finally, new transportation technologies, such as electric, battery-powered automated vehicles (AVs) adopted by public transportation networks, businesses, and residents, have the potential to reduce greenhouse gas emissions and combat contemporary transportation woes around pollution, congestion, and parking ${ }^{87}$. Cities such as Tempe, Arizona, USA, have implemented AVs as part of their Smart Mobility strategies in their Climate Action Plan ${ }^{88}$. High-speed electric trackless trams implemented at the city-scale are another green tech option for future cities, equipped with GPS and LIDAR technologies to move quickly and precisely through cities, all while reducing emissions. Such emerging technologies are proposed for climate change adaptation and urban regeneration in Australian cities, including Perth, Sydney, and Melbourne ${ }^{89}$.

Urban policymakers need updated information on human behavior and perceptions and how they relate to global and local environmental change. For example, seemingly basic questions about the value of urban green space or the social and cultural benefits of urban parks to diverse residents (answers that are essential to bring the innovations in nature-based solutions into planning, management, and design), are currently challenging to answer because adequate social data limit such social-ecological research. Big data, including social media data, can offer new opportunities to link research and decisionmaking with advanced data and computation ${ }^{12}$. Citizen science methods where urban residents monitor atmospheric conditions using smart devices (e.g., personal weather stations) are also providing new, crowdsourced data sets for monitoring and analyzing urban heat island patterns and intensity across urban regions $^{90}$ while engaging resident-level agency for potential climate change adaptation.

It is not only a question of adequate and informative data that link citizens to policy and planning, but importantly the political will of governing bodies to favor long-term proactive climate change adaptation changes over short-term or temporary byproducts (e.g., job loss). Governing bodies must also be wary that transforming urban landscapes into "smart cities" through technology (loT, big data, and automation) is connected to risks of deepening social divides linked with private asset ownership, access to information and knowledge, gentrification and displacement, neoliberal investment rationales, agendas of growth, and others. These consequences argue for managing the interdependences of social and technological, and potential unintended feedbacks between subsystems. Indeed, this is the challenge of managing SETS change for just climate resilience. Ultimately, urban change can be collectively achieved with city residents through digital technology that encourages cocreation, engagement, and participation across all social groups (e.g., JigsAudio technologies $)^{91}$ in combination with a political drive that supports equitable agency.

\section{CHALLENGES CAN BE WAYS FORWARD}

Urban SETS change can be proactively harnessed to build urban climate adaptation. Yet, the impacts of climate change on urban SETS and interactions across SETS systems are often unpredictable and make change implementation especially challenging. In addition, identifying or proactively supporting the mechanisms through which change can occur may be difficult in some urban and cultural contexts at the appropriate scale. Challenges and barriers can arise in urban systems and contexts to limit the effective implementation of this framework, and lead to outstanding issues for research and for global urban society:

- How can all urban residents be not mere spectators or victims of SETS change and climate change, but engaged players that can lead SETS to change for climate change adaptation?

- How can unforeseen shifts in social-ecological systems be translated into adaptive, rather than maladaptive, responses toward climate change?

- How can spatial and temporal asynchronies be realigned to match action with impact?

- How can cities promote effective and meaningful changes that are transferable across urban contexts?

- How can societal-level institutional bodies support just policy and governance actions to minimize trade-offs and upscale impacts?

- To what extent can we retrofit existing urban transformation and transition initiatives with climate change adaptation elements?

We conclude by addressing these complex questions arising from interactions within SETS as potential ways forward to harness social, ecological, and technological change and their interactions for positive urban climate change adaptation.

\section{Context-dependent adaptation}

It is not always possible to standardize, retrofit, and design SET change toward climate change adaptation for all cities. As "one size does not fit all', what works in a particular urban context, and at a specific point in time, does not ensure that this will be universally effective. Cities vary greatly in what specific climaterelated challenges they are facing, and what infrastructure and technology is already in place. As shown in the application of climate change and the SETS framework, some cities and towns might not have the capacity, resources, decision-making power, social and political willingness, or governance structures to pursue changes when a window of opportunity for deliberate change arises $^{92}$. In emerging and developing countries, other more urgent priorities and development challenges might hamper the application of this framework, as often seen in more traditional efforts toward climate change adaptation ${ }^{93}$ (Fig. 1). Furthermore, urban residents within and across cities are highly heterogeneous in sociodemographics, and in their actual and perceived need, 
willingness, and capacity for change adaptation. Hence, with this framework, we argue for a vast array of opportunities-like the diverse SETS changes that are already inevitably happening across cities-to retrofit urban climate change adaptation and complement other SETS frameworks. Local urban managers could tailor this framework to their context through the filter of their own knowledge. Here, stakeholders can prototype climate change adaptation changes locally, through safe-to-fail approaches (e.g., Fig. $2 A)^{94}$.

\section{Temporal asynchronicity}

Urban systems are driven by unpredictable feedback loops, multiscalar interactions, and legacies, all likely to occur asynchronously ${ }^{1}$. This is also true for urban climate change impacts, with adaptive responses likely to vary at different spatial and temporal scales $^{94,95}$. Small incremental SETS change can be possible but often comes in disruptive and abrupt ways (Fig. 2B), leaving small windows of opportunity to plan for unpredictability and design effective strategies for climate change adaptation. The steady progression of climate change, coupled with the variability of urban SETS change, might create tensions or time lapses in results as cities change themselves. To create and plan for change for a constantly "moving" and adapting system requires an approach that accommodates uncertainty across space and time and the metagovernance and orchestration of changes across SETS systems ${ }^{3}$. This needs a longer-term perspective, stable power structures, and considering potential lags in responses of environmental and social systems. Moreover, this can be achieved by designing contingency plans that allow for different pathways and outcomes as a key ingredient for moving toward proactive change. The ideal is a response system that aligns and amplifies positive changes to a more complex response to urban SETS change that synchronizes adaptation across scales, urban contexts, and social milieu. Following a context-dependent approach (3.1), decision-makers can use guidelines superimposed with incentives (e.g., tax cuts) that steer climatically 'safe' behavioral change.

\section{Inequality in adaptation}

Changes must be leveraged through active participation and diverse collaboration across all levels of society, across the Global North and South, to stabilize the earth's climate ${ }^{3}$. Although cities can be engines of innovation ${ }^{96}$, innovations, such as those related to technology and big data, might be generated by corporations and urban actors, but not necessarily aligned with environmental goals and values, specifically those related to climate change. New technology may thrive in un(der)-regulated markets and are associated with issues around political surveillance, privacy, and corporate power of automation ${ }^{71}$. Furthermore, technological uptake for climate change adaptation can hamper strides to improve urban social equity and justice ${ }^{97}$; higher resources of early technology adopters might disproportionately allow access to better technology and underlying benefits while exacerbating social divides with other social groups less capable of early technology adoption or access ${ }^{98}$. The question of whether and who should regulate SETS change for climate change adaptation should be explicitly addressed by local and international governance and policies, and not left to market devices. Inclusive governance at both local and global scales can help mitigate potential issues around equity and justice in climate change action and should establish policies that provide equitable access and distribution of opportunities for adaptation ${ }^{99}$ (Fig. 1A).

\section{Transform barriers into potential solutions}

Many of the challenges to urban climate adaptation are due to the hybrid character of SETS. The intrinsic hybridity and complexity of SETS cannot be simply solved as it is an inherent property of urban systems. Indeed, this hybridity means that SETS change can be responsible for major changes to the global climate, while also setting the seed for solutions to climate change. The framework of ideas proposed in this paper focuses on the latter scenario. While this complexity seems somewhat limiting, we can work around this complexity to find current progressive, integrated, and scalable solutions to climate change within and across different dimensions of SETS at different spatial and social scales. Where existing urban transitions are already occurring, these could benefit from the introduction of climate change adaptation elements. Rather than subsystem change, we must look also toward interactions between and among urban systems as a true potential opportunity for climate adaptation (Fig. 1). Urban scholars, policymakers, and local communities have concepts and tools to better than superficially understand and address it. Thus, it is up to local urban managers to adapt these ideas to their local context, to flip the coin, and change how the current climate narrative is understood and acted upon. What we suggest here is that urban change, regardless of its ecological, technological, or social nature, must be translated as an opportunity, rather than a burden. As a momentous occasion to increase the capacity of our cities and their residents to deal with and thrive under a changing climate.

\section{Reporting summary}

Further information on research design is available in the Nature Research Reporting Summary linked to this article.

\section{DATA AVAILABILITY}

The authors have no data to report.

Received: 6 June 2020; Accepted: 24 February 2021;

Published online: 25 March 2021

\section{REFERENCES}

1. Elmqvist, T. et al. Sustainability and resilience for transformation in the urban century. Nat. Sustain. 2, 267-273 (2019).

2. McPhearson, T. et al. Advancing urban ecology toward a science of cities. Bioscience 66, 198-212 (2016).

3. Otto, I. M. et al. Social tipping dynamics for stabilizing Earth's climate by 2050. Proc. Natl. Acad. Sci. USA. https://doi.org/10.1073/pnas.1900577117 (2020).

4. Haase, D., et al. Global urbanization: perspectives and trends. in Urban Planet: Knowledge towards Sustainable Cities (eds Elmqvist, T. et al.) 19-44 (Cambridge University Press, 2018).

5. Lin, B. B. \& Fuller, R. A. Sharing or sparing? How should we grow the world's cities? J. Appl. Ecol. 50, 1161-1168 (2013).

6. Markolf, S. A. et al. Interdependent Infrastructure as Linked Social, Ecological, and Technological Systems (SETSs) to Address Lock-in and Enhance Resilience. Earth's Future 6, 1638-1659 (2018).

7. Seto, K. C., Guneralp, B. \& Hutyra, L. R. Global forecasts of urban expansion to 2030 and direct impacts on biodiversity and carbon pools. Proc. Natl. Acad. Sci. USA 109, 16083-16088 (2012).

8. Ossola, A. et al. The provision of urban ecosystem services throughout the private-social-public domain: a conceptual framework. Cities Environ. 11, 1-15 (2018).

9. Aronson, M. F. J. et al. Hierarchical filters determine community assembly of urban species pools. Ecology 97, 2952-2963 (2016).

10. Groffman, P. M. et al. Ecological homogenization of urban USA. Front. Ecol. Environ. 12, 74-81 (2014).

11. Alberti, M. et al. The complexity of urban eco-evolutionary dynamics. Bioscience. https://doi.org/10.1093/biosci/biaa079 (2020).

12. llieva, R. T. \& Mcphearson, T. Social-media data for urban sustainability. Nat. Sustain. 1 (2018).

13. Hamblin, A. L., Youngsteadt, E. \& Frank, S. D. Wild bee abundance declines with urban warming, regardless of floral density. Urban Ecosyst. 21, 419-428 (2018). 
14. Rosenzweig, C., Solecki, W., Hammer, S. A. \& Mehrotra, S. Cities lead the way in climate-change action. Nature 467, 909-911 (2010).

15. Solecki, W. et al. City transformations in a $1.5^{\circ} \mathrm{C}$ warmer world. Nat. Climate Change 8, 177-181 (2018).

16. Ürge-Vorsatz, D. I. et al. Locking in positive climate responses in cities. Nat. Clim. Change 8, 174-177 (2018).

17. Pachauri, R. K. et al. Climate change 2014: synthesis report. Contribution of Working Groups I, II and III to the fifth assessment report of the Intergovernmental Panel on Climate Change. (IPCC, 2014).

18. Bai, X. et al. Defining and advancing a systems approach for sustainable cities. Curr. Opin. Environ. Sustain. 23, 69-78 (2016).

19. Frantzeskaki, N. et al. Nature-based solutions for urban climate change adaptation: linking science, policy, and practice communities for evidence-based decision-making. Bioscience 69, 455-466 (2019).

20. Andersson, E. et al. Enabling green and blue infrastructure to improve contributions to human well-being and equity in urban systems. Bioscience 69, 566-574 (2019).

21. Matthews, T., Lo, A. Y. \& Byrne, J. A. Reconceptualizing green infrastructure for climate change adaptation: barriers to adoption and drivers for uptake by spatial planners. Landsc. Urban Plan. 138, 155-163 (2015).

22. McCarthy, M. P., Best, M. J. \& Betts, R. A. Climate change in cities due to global warming and urban effects. Geophys. Res. Lett. 37, n/a-n/a (2010).

23. Burley, H. et al. Substantial declines in urban tree habitat predicted under climate change. Sci. Total Environ. 685, 451-462 (2019).

24. Xu, C., Kohler, T. A., Lenton, T. M., Svenning, J. \& Scheffer, M. Future of the human climate niche. Proc. Natl Acad Sci. 117, 11350-11355 (2019).

25. Bhowmik, A. K., McCaffrey, M. S., Ruskey, A. M., Frischmann, C. \& Gaffney, O. Powers of 10: seeking "sweet spots" for rapid climate and sustainability actions between individual and global scales. Environ. Res. Lett. https://doi.org/10.1088/ 1748-9326/ab9ed0 (2020).

26. Westley, F. et al. Tipping toward sustainability: emerging pathways of transformation. in Ambio 40, 762-780 (Springer, 2011).

27. Frantzeskaki, N. \& Rok, A. Co-producing urban sustainability transitions knowledge with community, policy and science. Environ. Innov. Soc. Transit. 29, 47-51 (2018).

28. Brink, E. \& Wamsler, C. Collaborative governance for climate change adaptation: mapping citizen-municipality interactions. Environ. Policy Gov. 28, 82-97 (2018).

29. Frantzeskaki, N., Borgström, S., Gorissen, L., Egermann, M. \& Ehnert, F. NatureBased Solutions Accelerating Urban Sustainability Transitions in Cities: Lessons from Dresden, Genk and Stockholm Cities. https://doi.org/10.1007/978-3-319-56091-5_5 (2017).

30. David Tàbara, J. et al. Positive tipping points in a rapidly warming world. Curr. Opin. Environ. Sustain. https://doi.org/10.1016/j.cosust.2018.01.012 (2018).

31. Habeeb, D., Vargo, J. \& Stone, B. Rising heat wave trends in large US cities. Nat. Hazards 76, 1651-1665 (2015).

32. Paul, S., Ghosh, S., Mathew, M. \& Devanand, A. Increased spatial variability and intensification of extreme monsoon rainfall due to urbanization. Sci. Rep. https:// doi.org/10.1038/s41598-018-22322-9 (2018).

33. IPCC. Climate Change and Land: An IPCC Special Report on Climate Change, Desertification, Land Degradation, Sustainable Land Management, Food Security, and Greenhouse Gas Fluxes in Terrestrial Ecosystems. (2018).

34. Gill, S. E., Handley, J. F., Ennos, A. R. \& Pauleit, S. Adapting cities for climate change: the role of the green infrastructure. Built Environ. 33, 115-133 (2007).

35. Mathias, J. D. et al. Exploring non-linear transition pathways in social-ecological systems. Sci. Rep. 10, 1-12 (2020).

36. Alberti, M., Mcphearson, T. \& Gonzalez, A. Embracing Urban Complexity Cities in the Context of the Anthropocene. in Urban Planet: Knowledge towards Sustainable Cities. 45-67 (Cambridge University Press, 2018).

37. Fischer, L. K. et al. Public attitudes toward biodiversity-friendly greenspace management in Europe. Conserv. Lett. 13, 1-11 (2020).

38. Habersaat, K. B. et al. Ten considerations for effectively managing the COVID-19 transition. Nat. Hum. Behav. 4, 677-687 (2020).

39. Lorenzoni, I., Nicholson-Cole, S. \& Whitmarsh, L. Barriers perceived to engaging with climate change among the UK public and their policy implications. Glob. Environ. Change 17, 445-459 (2007).

40. Whitmarsh, L., Lorenzoni, I. \& O'Neill, S. Engaging the Public with Climate Change: Behaviour Change and Communication. (Routledge, 2012).

41. Wahlström, M., Kocyba, P., De Vydt, M. \& de Moor, J. Protest for a future: Composition, Mobilization and Motives of the Participants in Fridays For Future Climate Protests on 15 March, 2019 in 13 European cities. (2019).

42. Borgström, S. Balancing diversity and connectivity in multi-level governance settings for urban transformative capacity. Ambio 48, 463-477 (2019).

43. Loorbach, D., Wittmayer, J., Avelino, F., von Wirth, T. \& Frantzeskaki, N. Transformative innovation and translocal diffusion. Environ. Innov. Soc. Transit. 35, 251-260 (2020).
44. Wortman, S. E. \& Lovell, S. T. Environmental challenges threatening the growth of urban agriculture in the United States. J. Environ. Qual. 42, 1283-1294 (2013).

45. Clarke, M., Davidson, M., Egerer, M., Anderson, E. \& Fouch, N. The underutilized role of community gardens in improving cities' adaptation to climate change: a review. People Place and Policy 12, 241-251 (2019).

46. Lin, B. B. \& Egerer, M. H. Global social and environmental change drives the management and delivery of ecosystem services from urban gardens: a case study from Central Coast, California. Glob. Environ. Change 60, 1-10 (2020).

47. Egerer, M. H., Lin, B. B., Threlfall, C. G. \& Kendal, D. Temperature variability influences urban garden plant richness and gardener water use behavior, but not planting decisions. Sci. Total Environ. 646, 111-120 (2019).

48. Carmin, J., Anguelovski, I. \& Roberts, D. Urban climate adaptation in the global south: planning in an emerging policy domain. J. Plan. Educ. Res. 32, 18-32 (2008).

49. Du, J. In Gorakhpur, India, Citizens Use Nature to Prevent Floods. (World Resources Institute, 2019).

50. Knaus, M. \& Haase, D. Green roof effects on daytime heat in a prefabricated residential neighbourhood in Berlin, Germany. Urban For. Urban Green. 53, 126738 (2020).

51. Bai, X. et al. Networking urban science, policy and practice for sustainability. Curr. Opin. Environ. Sustain. 39, 114-122 (2019).

52. van der Jagt, A. P. N. et al. Co-creating urban green infrastructure connecting people and nature: a guiding framework and approach. J. Environ. Manage. 233, 757-767 (2019).

53. Buijs, A. et al. Mosaic governance for urban green infrastructure: upscaling active citizenship from a local government perspective. Urban For. Urban Green. 40, 53-62 (2019).

54. Acuto, M. Give cities a seat at the top table. Nature 537, 611-613 (2016).

55. Archer, D. et al. Moving towards inclusive urban adaptation: approaches to integrating community-based adaptation to climate change at city and national scale. Clim. Dev. 6, 345-356 (2014).

56. Bai, X. Six research priorities for cities and climate change. Nature 555, 23-25 (2018).

57. Ignatieva, M. \& Hedblom, M. An alternative urban green carpet. Science $\mathbf{3 6 2}$, 148-149 (2018).

58. Hobbie, S. E. \& Grimm, N. B. Nature-based approaches to managing climate change impacts in cities. Philos. Trans. R. Soc. B 375, 1-15 (2020).

59. Kleerekoper, L., Van Esch, M. \& Salcedo, T. B. How to make a city climate-proof, addressing the urban heat island effect. Resour. Conserv. Recycl. 64, 30-38 (2012).

60. Africa, J., Heerwagen, J., Loftness, V. \& Ryan Balagtas, C. Biophilic design and Climate Change: performance parameters for health. Front. Built Environ. 5, 1-5 (2019).

61. SenUVK. Strategie zum Schutz und zur Förderung von Bienen und Anderen Bestäubern in Berlin. (2019).

62. Cabral, I., Costa, S., Weiland, U. \& Bonn, A. Nature-Based Solutions to Climate Change Adaptation in Urban Areas. 237-253 (2017).

63. Pauleit, S., Zölch, T., Hansen, R., Randrup, T. B. \& van den Bosch, C. K. Naturebased solutions and climate change-four shades of green. in Nature-Based Solutions to Climate Change Adaptation in Urban Areas. 29-49 (Springer, Cham, 2017).

64. Depietri, Y. \& McPhearson, T. Changing urban risk: 140 years of climatic hazards in New York City. Clim. Change 148, 95-108 (2018).

65. Huang-Lachmann, J. T. \& Lovett, J. C. How cities prepare for climate change: comparing Hamburg and Rotterdam. Cities 54, 36-44 (2016).

66. Beatley, T. Handbook of biophilic city planning and design. Handbook of Biophilic City Planning and Design (Island Press-Center for Resource Economics, 2017). https://doi.org/10.5822/978-1-61091-621-9.

67. Kabisch, N. et al. Nature-based solutions to climate change mitigation and adaptation in urban areas and their rural surroundings. Ecol. Soc. 21, 1-15 (2016).

68. Kythreotis, A. P. et al. Citizen social science for more integrative and effective climate action: a science-policy perspective. Front. Environ. Sci. 7, 10 (2019).

69. Creutzig, F. et al. Upscaling urban data science for global climate solutions. Glob. Sustain. 2, 1-25 (2019).

70. Sarzynski, A. Public participation, civic capacity, and climate change adaptation in cities. Urban Clim. 14, 52-67 (2015).

71. Gulsrud, N. M. et al. 'Rage against the machine'? The opportunities and risks concerning the automation of urban green infrastructure. Landsc. Urban Plan. 180, 85-92 (2018).

72. Stokols, D. Social Ecology in the Digital Age: Solving Complex Problems in a Globalized World. (Academic Press, 2018).

73. Anderson, S. E. et al. The dangers of disaster-driven responses to climate change. Nat. Clim. Change. 8, 648-659 (2018).

74. Deng, D., Chen, L., Zhou, X. \& Zhao, Y. Smart city planning under the climate change condition. IOP Conf. Ser. Earth Environ. Sci. 81, 1-3 (2017). 
75. Alvear, O., Calafate, C. T., Cano, J. C. \& Manzoni, P. Crowdsensing in smart cities: overview, platforms, and environment sensing issues. Sensors 18, 1-28 (2018).

76. Bartos, M., Park, H., Zhou, T., Kerkez, B. \& Vasudevan, R. Windshield wipers on connected vehicles produce high-accuracy rainfall maps. Sci. Rep. 9, 1-9 (2019).

77. Barns, S., Cosgrave, E., Acuto, M. \& Mcneill, D. Digital infrastructures and urban governance. Urban Policy Res. 35, 20-31 (2017).

78. Chester, M. V. \& Allenby, B. Toward adaptive infrastructure: flexibility and agility in a non-stationarity age. Sustain. Resil. Infrastruct 4, 1-19 (2018).

79. Booysen, M. J., Visser, M. \& Burger, R. Temporal case study of household behavioural response to Cape Town's "Day Zero" using smart meter data. Water Res. 149, 414-420 (2019).

80. Enqvist, J. P. \& Ziervogel, G. Water governance and justice in Cape Town: an overview. Wiley Interdiscip. Rev. Water 6, e1354 (2019).

81. Eckert, R. \& Schinkel, U. Liveable City TP. Ho Chi Minh-Adaptation as response to impacts of climate change. Proc. REAL CORP 2009 Tagungsband 313-323 (2009).

82. Wamsler, C. \& Brink, E. Interfacing citizens' and institutions' practice and responsibilities for climate change adaptation. Urban Clim. 7, 64-91 (2014).

83. Akbari, H., Damon Matthews, H. \& Seto, D. The long-term effect of increasing the albedo of urban areas. Environ. Res. Lett. 7, 1-10 (2012).

84. Lim, X. Z. The super-cool materials that send heat to space. Nature 577, 18-20 (2020).

85. Zhou, L. et al. A polydimethylsiloxane-coated metal structure for all-day radiative cooling. Nat. Sustain. 2, 718-724 (2019).

86. Shur, Y. \& Goering, D. J. Climate Change and Foundations of Buildings in Permafrost Regions. in Permafrost Soils 251-260 (Springer, Berlin, Heidelberg, 2008).

87. Walker, W. E. \& Marchau, V. A. W. J. Dynamic adaptive policymaking for the sustainable city: the case of automated taxis. Int. J. Transp. Sci. Technol. 6, 1-12 (2017).

88. Keeler, B. L. et al. Social-ecological and technological factors moderate the value of urban nature. Nat. Sustain. 2, 29-38 (2019).

89. Newman, P. Cool planning: How urban planning can mainstream responses to climate change. Cities 103, 102651 (2020).

90. Meier, F., Fenner, D., Grassmann, T., Otto, M. \& Scherer, D. Crowdsourcing air temperature from citizen weather stations for urban climate research. Urban Clim. 19, 170-191 (2017)

91. Wilson, A. \& Tewdwr-Jones, M. Let's draw and talk about urban change: deploying digital technology to encourage citizen participation in urban planning. Environ. Plan. B Urban Anal. City Sci. 47, 1588-1604 (2019).

92. Kitchin, R. The real-time city? Big data and smart urbanism. GeoJournal 79, 1-14 (2014).

93. Anguelovski, I., Chu, E. \& Carmin, J. Variations in approaches to urban climate adaptation: experiences and experimentation from the global South. Glob. Environ. Chang. 27, 156-167 (2014).

94. Kim, Y. et al. Fail-safe and safe-to-fail adaptation: decision-making for urban flooding under climate change. Clim. Change 145, 397-412 (2017).

95. Kim, Y., Chester, M. V., Eisenberg, D. A. \& Redman, C. L. The infrastructure trolley problem: positioning safe-to-fail infrastructure for climate change adaptation. Earth's Future https://doi.org/10.1029/2019EF001208 (2019).

96. Bettencourt, L. M. A., Lobo, J., Helbing, D., Kuhnert, C. \& West, G. B. Growth, innovation, scaling, and the pace of life in cities. Proc. Natl Acad. Sci. USA 104 7301-7306 (2007).

97. Scoville-Simonds, M., Jamali, H. \& Hufty, M. The hazards of mainstreaming: climate change adaptation politics in three dimensions. World Dev. 125, 104683 (2020)

98. Nguyen, T. M. P. \& Davidson, K. Contesting green technology in the city: technoapartheid or equitable modernisation? Int. Plan. Stud. 22, 400-414 (2017).
99. Jabareen, Y. Planning the resilient city: concepts and strategies for coping with climate change and environmental risk. Cities 31, 220-229 (2013).

\section{ACKNOWLEDGEMENTS}

M.E. was supported by the International Postdoc Initiative at the Technical University of Berlin during this work. T.M. is supported by the US National Science Foundation under Grant nos. 1444755, 1927167, and 1934933, and T.M. and E.A. are supported by NordForsk through funding to the SMARTer Greener Cities project (\# 95377).

\section{AUTHOR CONTRIBUTIONS}

M.E. and A.O. initiated the idea for the paper. M.E. led the data collection, writing of and revising the paper. All authors contributed to the data collection and paper writing and revising.

\section{FUNDING}

Open Access funding enabled and organized by Projekt DEAL.

\section{COMPETING INTERESTS}

The authors declare no competing interests.

\section{ADDITIONAL INFORMATION}

Supplementary information The online version contains supplementary material available at https://doi.org/10.1038/s42949-021-00024-y.

Correspondence and requests for materials should be addressed to M.E.

Reprints and permission information is available at http://www.nature.com/ reprints

Publisher's note Springer Nature remains neutral with regard to jurisdictional claims in published maps and institutional affiliations.

Access This article is licensed under a Creative Commons Attribution 4.0 International License, which permits use, sharing, adaptation, distribution and reproduction in any medium or format, as long as you give appropriate credit to the original author(s) and the source, provide a link to the Creative Commons license, and indicate if changes were made. The images or other third party material in this article are included in the article's Creative Commons license, unless indicated otherwise in a credit line to the material. If material is not included in the article's Creative Commons license and your intended use is not permitted by statutory regulation or exceeds the permitted use, you will need to obtain permission directly from the copyright holder. To view a copy of this license, visit http://creativecommons. org/licenses/by/4.0/.

C The Author(s) 2021 